\title{
JOSÉ DE HERMOSILLA Y EL RETABLO DE IRURITA EN NAVARRA
}

\author{
POR \\ MARÍA TERESA CRUZ YÁBAR \\ Licda. Universidad Complutense
}

The finding of some archival documents about the Irurita's altarpiece has permitted us to affirm that the project belong to José Hermosilla. This altarpiece ist pioneer of the Neoclasicisme in Navarra and its plan can be compared with ther architectonics propositions, solucions and models included by Hermosilla in his Cours of Architecture (1750). Also, the sculptor of the middle of figures ist identified and formuled one proposition about the rest.

El reciente Catálogo monumental de Navarra, en su tomo V* editado en 1994, se refiere al retablo mayor de la iglesia parroquial de Irurita (Fig. 1) en el valle del Baztán fechándolo en torno a 1760 , sin definir su estilo ni comentar su rarísima hechura y su significado en el contexto del retablo navarro de la época. Respecto a su escultura, la clasifica como de clara influencia madrileña por su refinamiento ${ }^{1}$. Otra reciente publicación sobre el retablo navarro utiliza la fotografía del de Irurita para encabezar el capítulo titulado El retablo del rococó cortesano sin que su texto lo mencione luego, aparte de la implícita valoración que supone esa imagen ${ }^{2}$. La documentación que conserva la iglesia de Irurita, entre ella el libro de fábrica correspondiente a los años en que se labró este retablo y su escultura, no proporciona el menor dato acerca de su autor y ni siquiera se puede deducir por otras noticias las fechas en que se pudo ejecutar ${ }^{3}$.

El retablo ocupa todo el ábside curvilíneo y la media naranja, adaptándose a él. La estructura podría recordar, por tanto, los retablos tardobarrocos, pero no lo hace, y nada en él presenta el menor parentesco con las artificiosas envolturas que ideara José Benito de Churriguera y que en la época a que corresponde este retablo proliferaban en Navarra. Sus tableros son lisos, apenas decorados, y la claridad preside el conjunto; sus líneas son continuas, sin quiebros destacables, con friso corrido sólo roto por el frontón que corona la calle central. En el centro, en la actualidad vacío, debió existir un sagrario, quizá el que se guarda en la sacristía, en forma de templete.

\footnotetext{
Catálogo Monumental de Navarra, T. II**, Pamplona 1994, 384.

2 María Concepción García Gainza, «El retablo cortesano», en El arte en Navarra, Pamplona 1994, 466-467.

${ }^{3}$ Archivo Parroquial de Irurita, Libro de Fábrica 1º, 1683-1842.
} 
En cuanto al detalle de las esculturas que decoran el retablo, diremos que la hornacina central está ocupada por una imagen de talla, de tamaño casi natural, del Salvador (Fig. 2) sobre la esfera del mundo envuelta parcialmente en nubes entre las que aparecen tres querubines; en las calles se sitúan cuatro estatuas de talla de la misma altura: en los entrepaños más cercanos al Salvador, San José con el Niño (Fig. 3) y San Francisco Javier (Fig. 4), y en los extremos San Juan Bautista (Fig. 5) y San Eutropio (Fig. 6) (al que el catálogo de Navarra identifica como San Fermín); en la parte superior de las calles entre pilastras, sendos relieves cuadrados colocados encima de las tallas de los extremos ilustran escenas de los santos que quedan debajo: el Bautismo de Jesús (Fig. 7) sobre san Juan Bautista y el Martirio de san Eutropio (también de san Fermín para el catálogo de Navarra) (Fig. 8) sobre el obispo; en el banco, debajo de los intercolumnios, dos bajorrelieves rectangulares alargados de la Adoración de los pastores (Fig. 9) a la izquierda y de la Epifanía (Fig. 10) a la derecha y bajo las cuatro pilastras que bordean las calles extremas, relieves prácticamente cuadrados de los cuatro Evangelistas, que son, de izquierda a derecha: San Marcos, San Juan, San Mateo y San Lucas, todos mostrando sus evangelios y acompañados de los signos del Tetramorfos.

Nada se sabía del autor o autores del retablo y de sus esculturas ni del posible comitente, como ya se ha dicho. Sin embargo, varios documentos custodiados en la Real Academia de San Fernando de Madrid arrojan cierta luz sobre diversos aspectos de la ejecución de este retablo, si bien algunos otros quedan aún sin esclarecer.

En primer lugar, existe un expediente ${ }^{4}$ que refiere con detalle la consulta que acerca de un proyectado retablo mayor de Irurita formulaba José Ignacio de Goyeneche en carta de 7 de junio de 1770 dirigida al viceprotector de la Academia don Vicente Pignatelli. Con la carta le remitía la traza que había diseñado Juan José de Echarri -arquitecto y tallista pamplonés- para que fuera vista por la Academia. Tres días después, el 10 de junio, se trataba del asunto en la junta ordinaria, que rechazó la traza. El acuerdo hacía constar lo siguiente: «Reprobado enteramente». El acta de la junta de ese día da a conocer más detalles: que el diseño fue examinado por los vocales de Arquitectura y académicos de mérito José de Hermosilla y Luis de Lorenzana, los directores Ventura Rodríguez y Diego Villanueva y el teniente director Miguel Fernández y que todos coincidieron en calificarlo de «monstruoso, sin idea, sin arte, sin regla ni buen gusto», en lo que estuvieron de acuerdo así mismo los profesores de pintura y escultura presentes ${ }^{5}$.

El mismo Pignatelli se encargó de comunicar el dictamen a Goyeneche, expresándole la voluntad de la Academia de ayudar «a desterrar el mal gusto y a que no se gaste el dinero en obras que nos afrentan». Le señalaba la conveniencia de traer «la planta y corte interior de la referida parroquia, en diseños geométricos que señalen con exactitud la altura interior, la de las cornisas y ventanas, el sitio donde se ha de poner el retablo», y de indicar si se había de hacer de jaspe o madera y el caudal destinado a él. Obedeció el consultante, que se debió apresurar a reclamar las medidas y planos de la iglesia, ya que antes de un mes, el 6 de julio, los remitía a la Academia con la súplica de que «se sirba hazerlos presente a la Academia a fin de que en su vista y con presencia del citado diseño se forme otro arreglado y oportuno a la idea de aquellos naturales». Sin duda, los comitentes toleraban que el proyecto se modificara lo necesario para adecuarlo a las exigencias académicas, pero no tanto que no respetase su «idea», expresión con la que pensamos se referían los académicos a las apetencias de los clientes en cuanto a diversas características (forma en especial) que sin duda traslucía el proyecto rechazado.

\footnotetext{
4 Archivo de la R.A.S.F, Expediente 34, 2/2. Transcrito como documento 1.

5 Ibídem, Libro de Acuerdos de Juntas 3/83. Transcrito como documento 2.
} 

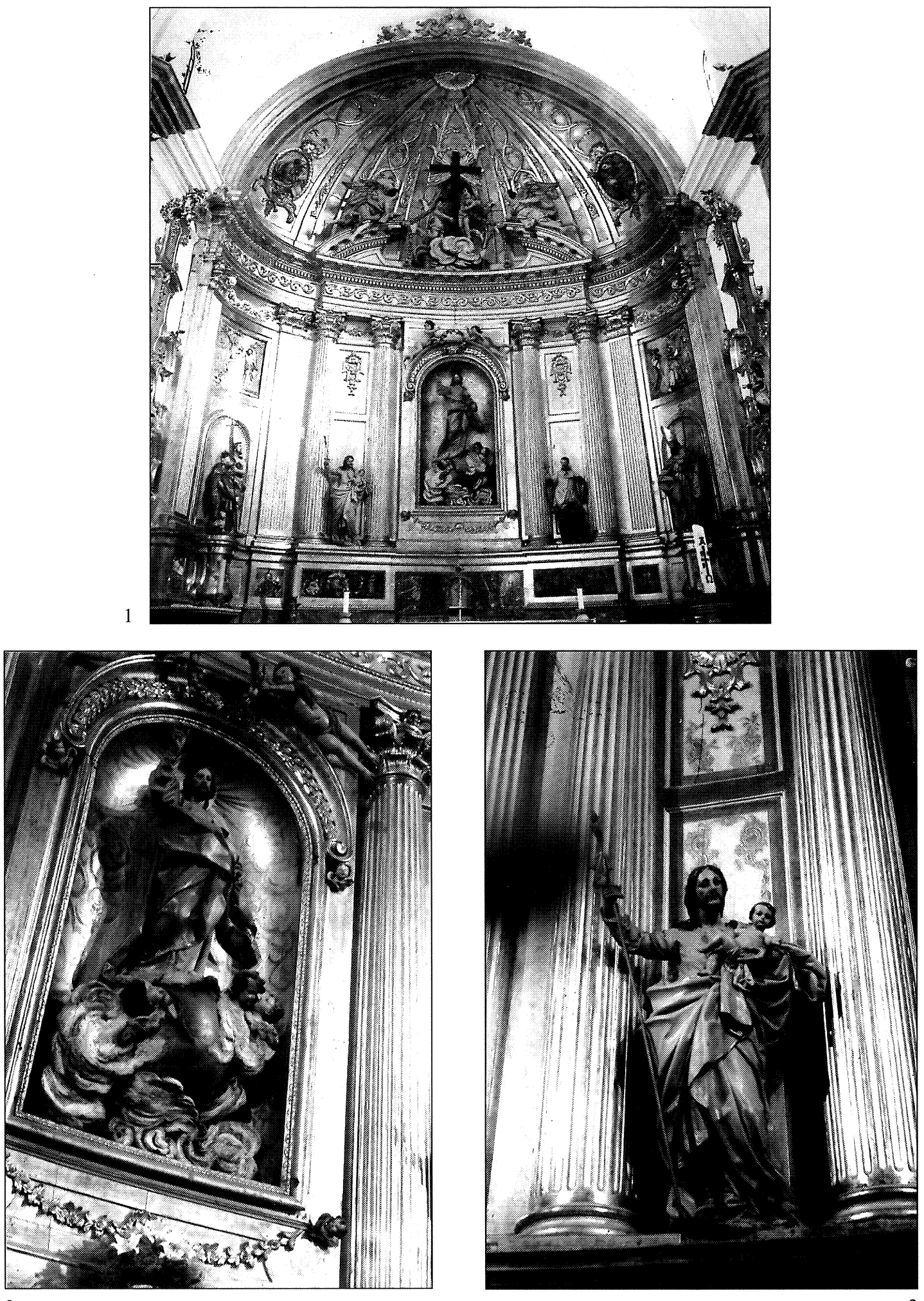

Fig. 1. Vista general del retablo.

Fig. 2. El Salvador.

Fig. 3. San José con el Niño.. 
En la siguiente junta ordinaria, el 8 de julio, se dio cuenta del estado del asunto y de cómo los interesados remitieron una planta de la iglesia y «una relación de las circunstancias que desean que tenga su retablo, expresando ha de ser de madera, cuyo material tienen prevenido y para costearlo de siete a ocho mil pesos». Termina el texto del acuerdo indicando que «este Viceprotector lo encargó al señor Académico de Honor Joseph de Hermosilla a quien se entregaron todos los antecedentes para formar el diseño». Estos datos y una referencia más a «los naturales que lo costean» apuntan a que los donantes del retablo eran residentes en Irurita, quizá alguna de las pudientes familias de la localidad, pero preferiblemente su Concejo. El plural que emplea la correspondencia para referirse a los «interesados» revela que éstos eran varios, lo que nos lleva a pensar que fueran los propios vecinos organizados en Concejo quienes pagaban el retablo. La madera procedería de los mismos bosques baztaneses, abundantes en hayedos, robles y otras especies arbóreas. José Ignacio de Goyeneche tenía un hermano, Juan Antonio, posible contribuyente a la hechura del retablo pues residía en Irurita, aunque la rama era originaria de Arizcun, también en Baztán; suponemos que ésta fue la vía por la que llegó a Madrid la traza del tallista navarro que fue tan criticada por la Academia ${ }^{6}$.

El viceprotector Pignatelli, como ya se ha dicho, encargó nuevo diseño a José de Hermosi$11 a^{7}$, académico de honor y antiguo director de arquitectura de la Academia. Su hermano Ignacio era Secretario de la Academia y hombre muy influyente. Hermosilla puso manos a la obra inmediatamente y el día 26 de julio remitía a la Academia el diseño del retablo. La carta adjunta del arquitecto explicaba el modo en que había cumplido el encargo y así refiere que había trazado un «plano, elevación y perfil» y también un sagrario o custodia. Se refiere igualmente a la supresión de los nichos superpuestos que al parecer existían en la traza primitiva y a la colocación de los cinco santos que había de llevar el retablo en una misma altura. Aconseja al artífice que haya de ejecutar el encargo que no yerre en su obra, para lo cual deberá hacer diseños parciales, «montear por partes el todo», según la expresión del teórico llerenense. En efecto, debiendo confiar en las medidas que se le habían proporcionado y no conociendo directamente el espacio que se tenía que cubrir, Hermosilla advertía de los errores que podía contener la traza en cuanto a la dimensión exacta de cada porción y su encaje con el resto.

\footnotetext{
${ }^{6}$ José Ignacio de Goyeneche y Martiarena, caballero de Santiago, había nacido en Elizondo el 1 de junio de 1705, hijo mayor de Juan de Gocheneche y Errázuriz, dueño de la casa solar de Martiarena, de Arizcun, y de María de Martiarena (capitulaciones matrimoniales en Arizcun a 21-7-1704); fue secretario de su Majestad y oficial de la Secretaría del Despacho de Guerra en ejercicio de decretos. Fueron sus hermanos Juan Antonio, Tomás, Justo Fausto, Manuel, Pedro Francisco y María Josefa. Tomás y Pedro Francisco, también residentes en Madrid y tesoreros del nuevo Palacio Real, y costearon en 1749, a devoción de su madre, María de Martiarena, la imagen de la Virgen del Rosario hecha por Juan Domingo Olivieri que se conserva en el colateral del lado de la epístola de la parroquial de Irurita. Juan Antonio, aunque nació a continuación de José Ignacio, continuó la rama familiar en el solar baztanés y fue seguramente el que puso en conocimiento de José Ignacio la noticia del proyecto de hacer el retablo (Datos familiares procedentes del expediente personal de la Orden de Santiago, A.H.N. exp.789, sign. 3597).

7 José de Hermosilla y Sandoval había nacido en Llerena, estudió en Sevilla filosofía y teología y después matemáticas en Madrid, ingresando en el cuerpo de Ingenieros del ejército y especializándose en arquitectura militar. Sirvió de trazador en las obras del Palacio Nuevo de Madrid; en 1748, el ministro Carvajal, conocedor de sus grandes dotes de arquitecto, le envió a Roma con una pensión, y le encargó, lo mismo que a Diego de Villanueva y a Ventura Rodríguez, la redacción de un Curso de Arquitectura que pudiera servir para la enseñanza de los alumnos de la futura Academia de Bellas Artes. En 1750 terminó este Curso y poco después regresó a Madrid. Fue designado director de Arquitectura de la Academia y teniente principal de arquitectura del Palacio Nuevo. Dimitió de estos cargos entre 1755 y 1756 y regresó al cuerpo de Ingenieros. En 1766 se le encomendó la tarea de levantar plantas y alzados de la Alhambra de Granada perfeccionando la obra que el pintor Diego Sánchez Sarabia había ejecutado pintándolos; inmediatamente después marchó con idéntica comisión a Córdoba y terminado el encargo, pasó al Escorial con otros ingenieros, levantando planos del Monasterio. En Madrid fueron elegidos sus diseños para el Hospital General de la Corte, y después de empezado éste por sus planos, fue sustituido por Sabatini, que los modificó sustancialmente. También fue seleccionado su proyecto para el futuro paseo del Prado madrileño, aunque su muerte en 1776 determinó que fuera Ventura Rodríguez quien se hiciera cargo de la dirección de las obras desde su inicio. Sobre este arquitecto, Carlos Sambricio, José de Hermosilla y el ideal historicista de la Ilustración, «Goya» 159 (1980), 140-151, y Delfín Rodríguez Ruiz, «De la utopia a la Academia. El tratado de arquitectura civil de José de Hermosilla», Fragmentos 3 (1989), 58-80.
} 

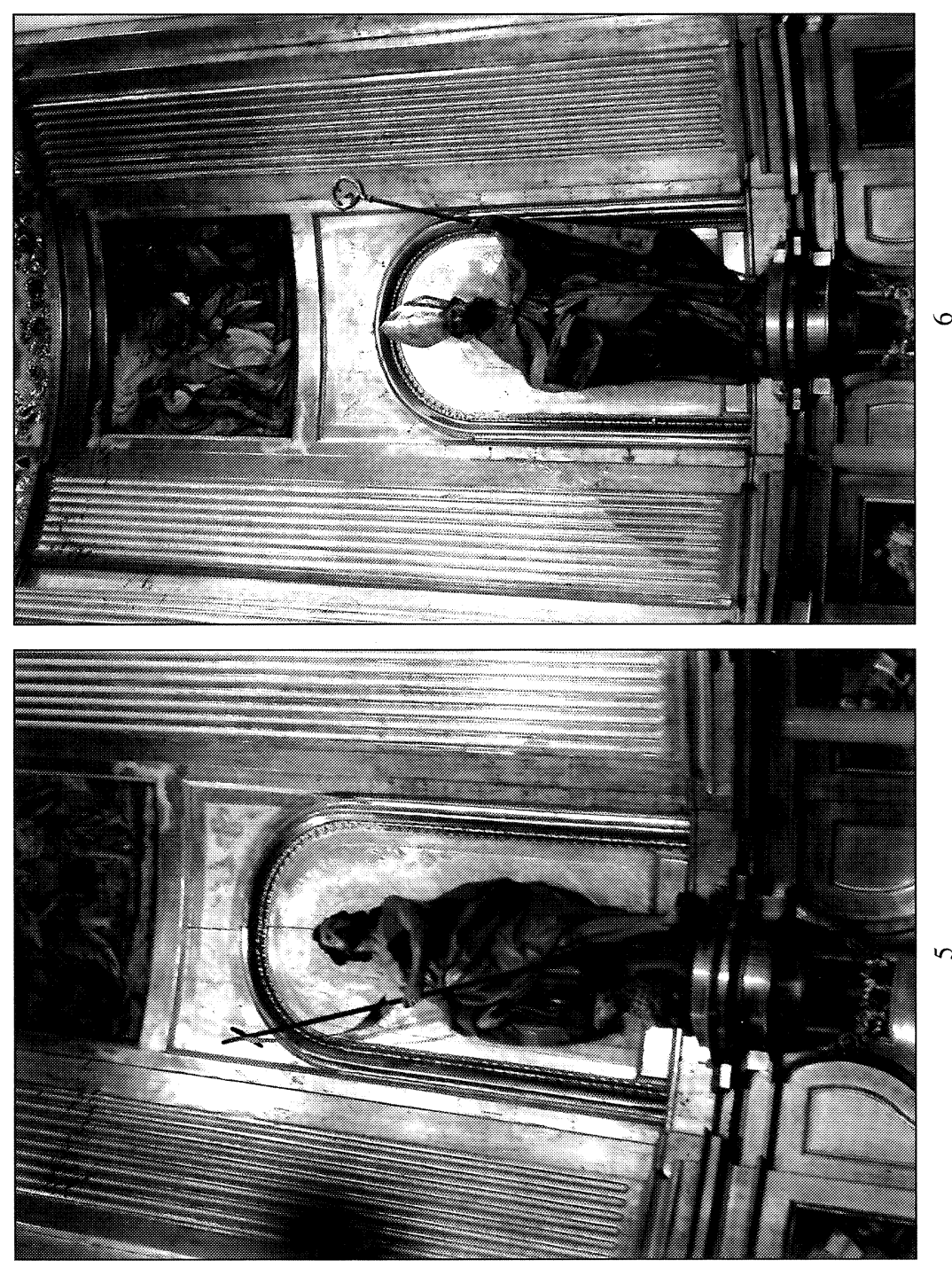
气ั้
है.
ชั
ถิำ
+riv

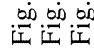

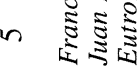

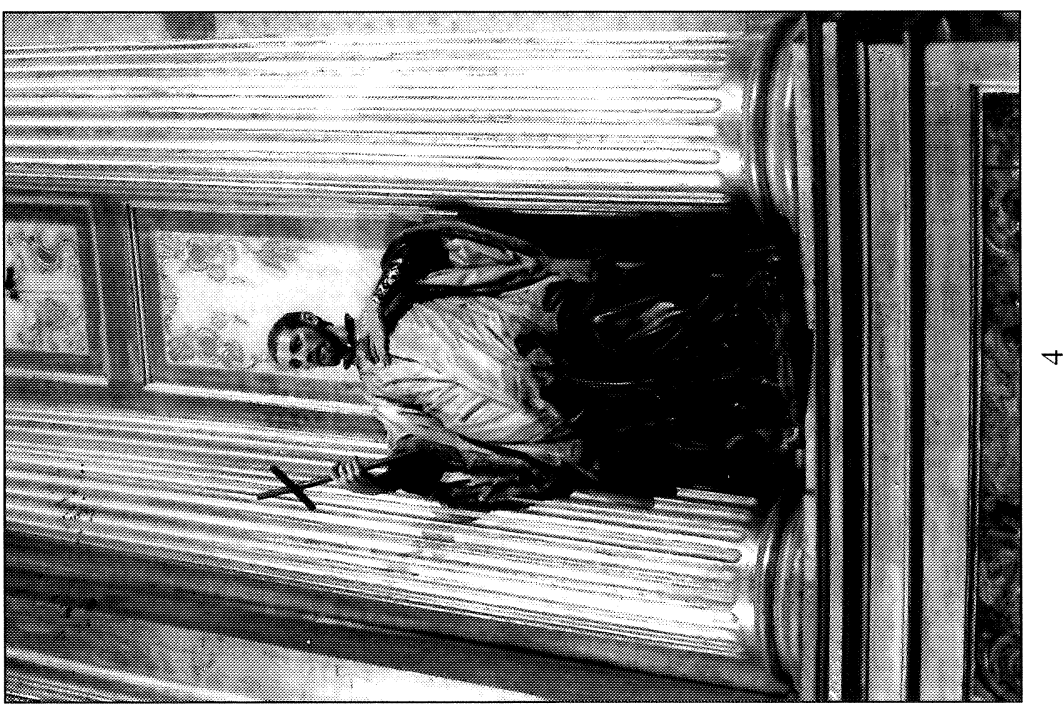


El 12 de agosto vio la traza la junta ordinaria de la Academia, la aprobó y ordenó remitirla al consultante. Al día siguiente, escribía Pignatelli a Goyeneche con la traza y el ofrecimiento de la Academia de ilustrar las dudas que pudieran tener los artífices que ejecutaran el retablo.

Nuevos datos sobre el retablo de Irurita, en este caso sobre su escultura, hallamos en el memorial que elevó Alfonso Bergaz de 8 de agosto de 1798 a la Academia detallando sus méritos, el cual incluye la lista de todas las obras realizadas por él hasta ese momento. En uno de sus párrafos dice así: «Para la Villa de Yrurita Reyno de Navarra dos estatuas, el Patriarca San Josef y San Francisco Javier del tamaño natural; así mismo cinco medallas, una del nacimiento del Hijo de Dios, idem el Bautismo de Christo, San Eutropio Obispo, San Juan bautizando a Christo, San Lucas y San Juan Evangelistas» ${ }^{8}$. Viñaza no utilizó este memorial para redactar su biografía del escultor o bien omitió esta obra y de este modo permaneció ignorado el dato para los estudiosos.

De las noticias hasta ahora expuestas parece posible deducir, por tanto, que el retablo fue construído por Juan José de Echarri a partir de agosto de 1770 según la traza de José de Hermosilla. El arquitecto navarro había terminado el año anterior junto a Ignacio Aizpurúa, con quien probablemente formaba compañía en aquél momento, la caja para el órgano de la iglesia de San Nicolás de Pamplona, obra inserta aún en un lenguaje rococó ${ }^{9}$. Ambos habían concursado, aunque al parecer no como tracistas sino sólo como realizadores, con una oferta para la ejecución del retablo de la Virgen del Camino en la iglesia pamplonesa de San Saturnino, obra adjudicada finalmente en febrero de 1770 a Juan Martín de Andrés, que debía tener buenas relaciones con Echarri puesto que le nombró tasador por su parte cuando entregó el retablo en $1773^{10}$. No se halla documentada ninguna otra obra de este maestro, por lo que si el retablo de Irurita salió de su mano como suponemos, sólo o acompañado de Aizpurúa, se trataría de una buena muestra de su correctísimo modo de ejecución como ensamblador.

Las modificaciones de la primitiva traza y lo que de ella queda tras la intervención de Hermosilla, según se deduce de la documentación, llevan a pensar que Echarri había trazado un retablo según la moda entonces vigente en Navarra, un tardobarroco con decoraciones rococós inspirado en las últimas creaciones del estilo de José Benito Churriguera en su versión guipuzcoana, estilo que García Gainza ${ }^{11}$ denomina «rococó cortesano» y considera introducido en Navarra por Tomás de Jaúregui a partir del retablo para la iglesia de Lesaca, terminado en 1754. La citada autora caracteriza ese modelo como «envolvente» por su aspecto de escenografía; son retablos que cubren totalmente las paredes del presbiterio, prolongados en cascarón hasta la techumbre, con entablamentos y frisos muy quebrados y cuerpos salientes y entrantes decorados con complicadas ménsulas, armazón de columnas del orden gigante, la calle central perforada con dos nichos, en el de abajo un tabernáculo y el de arriba, camarín para una imagen; en las calles laterales, hornacinas a la altura del segundo piso. Pues bien, el retablo de la Virgen del Camino ya citado responde a este estilo barroco y acredita su vigencia en Navarra al principio de la década de los setentas. En él se observa la colocación de esculturas en dos alturas diferentes, las del estilóbato, sobre ménsulas, abajo, y las de unas hornacinas en las calles laterales, formando un segundo piso. Sin duda era esa la colocación que Echarri pretendía para los dos santos que irían en los extremos del retablo de Irurita y que Hermosilla hizo descender al nivel de los otros, suprimiendo igualmente las hornacinas horadadas, ahora sólo

\footnotetext{
${ }^{8}$ R.A.S.F. 173-1/5. En la relación de las tallas para Irurita, Bergaz cita seis relieves después de haber anunciado que eran cinco; en efecto, debían ser sólo cinco porque enumera un «Bautismo de Cristo» y un «San Juan bautizando a Cristo», lo que supondría la existencia de dos relieves idénticos; sólo se halla un bautismo, situado encima de la imagen de San Juan Bautista.

${ }^{9}$ Catálogo Monumental de Navarra, T. V***, 156.

${ }_{10}$ Catálogo Monumental de Navarra, T. V***, 127-128.

1 El arte en Navarra... cit., 466-467.
} 

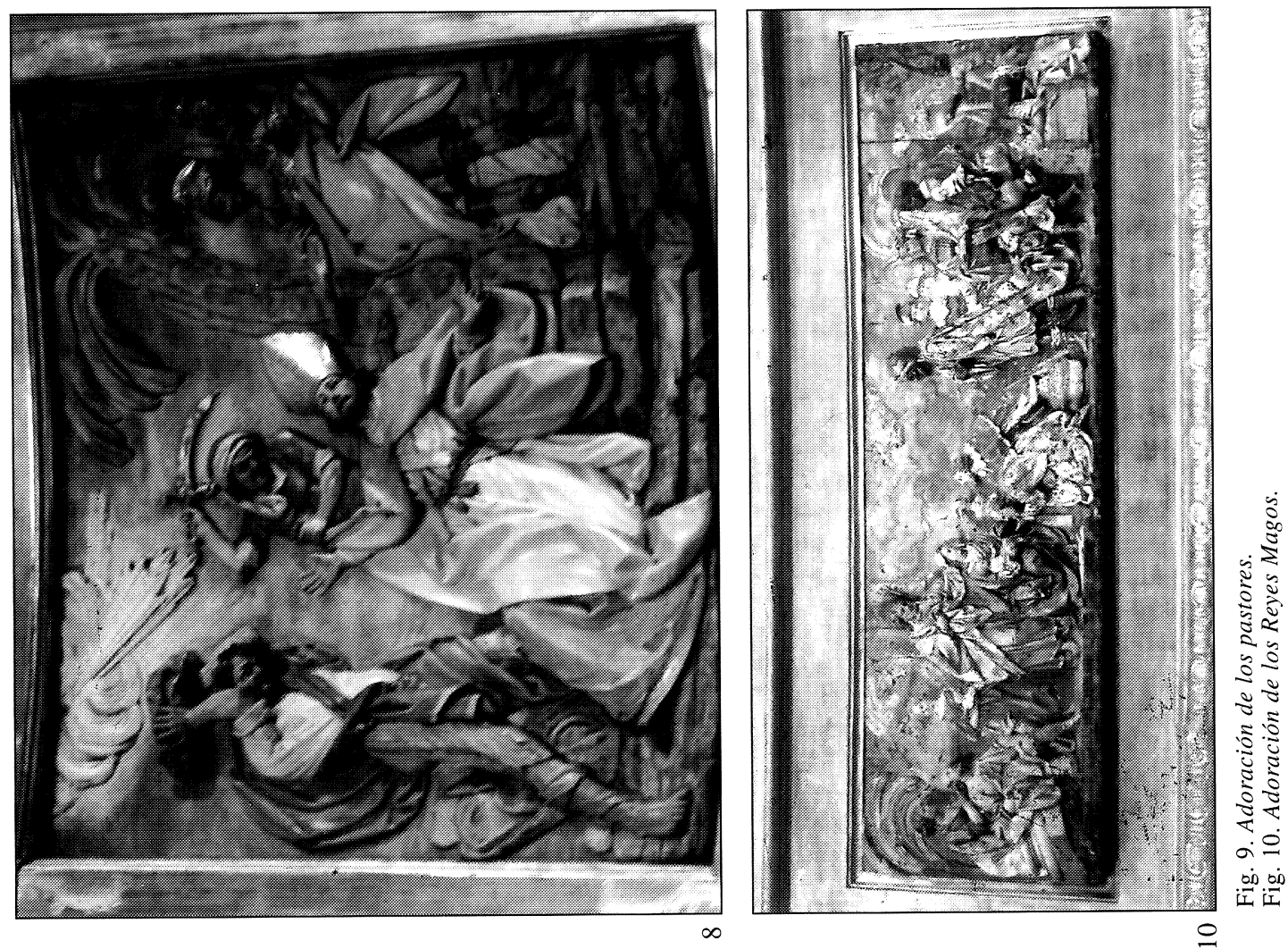

$r$

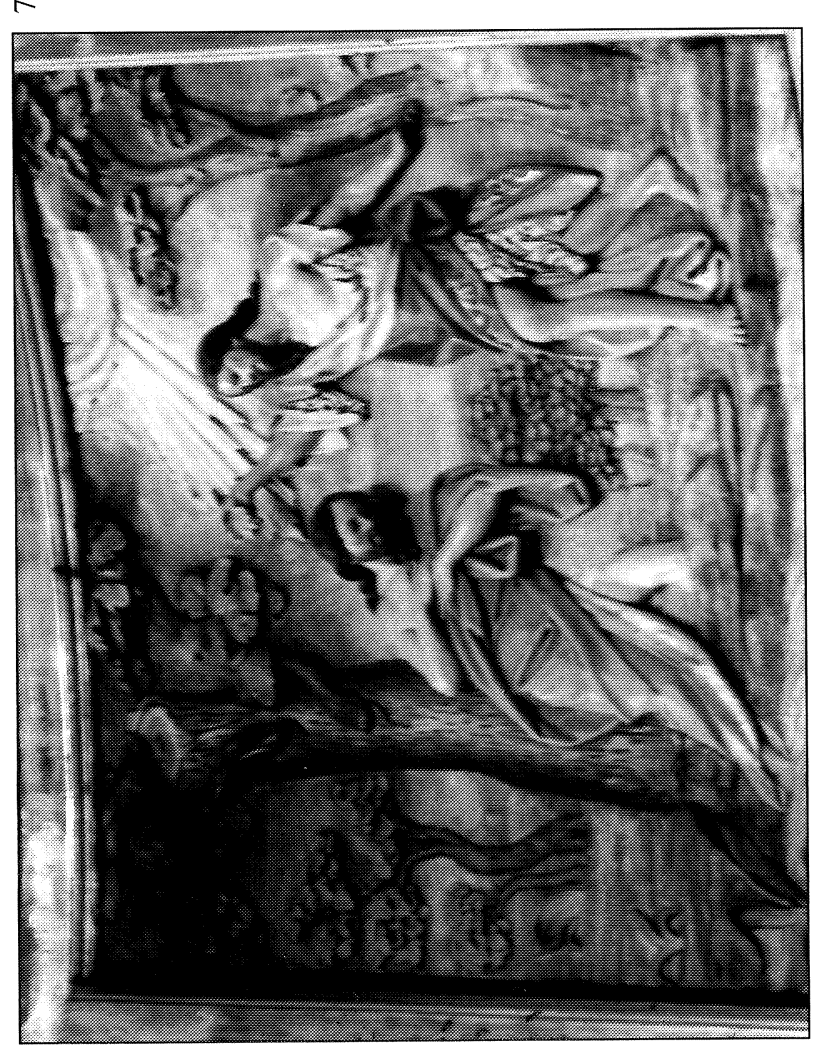

a

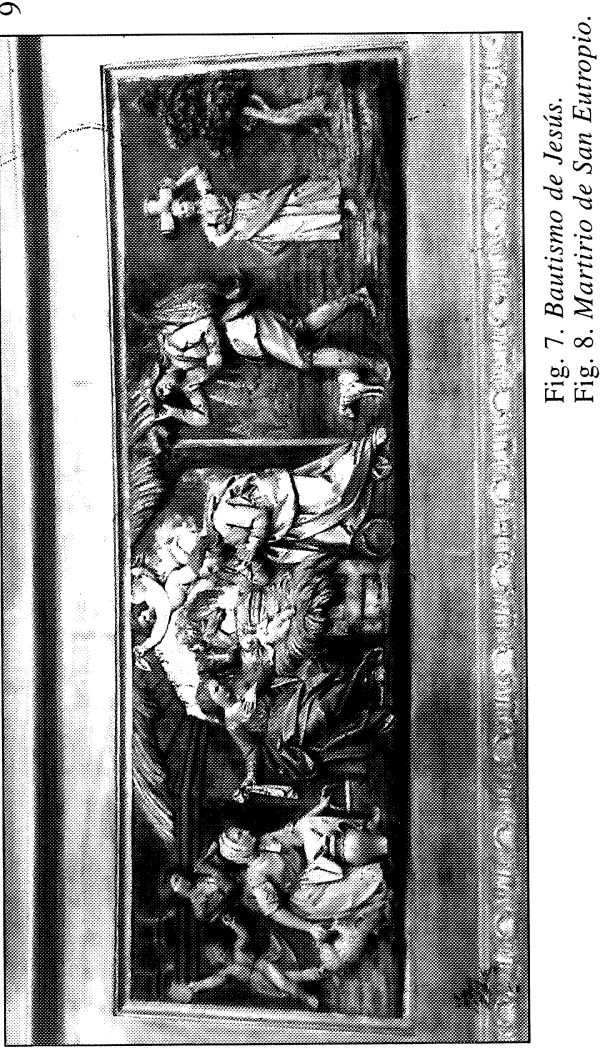


insinuadas por una ligera moldura. El madrileño conserva, sin embargo, las ménsulas del estilóbato, muy simplificadas y desornamentadas, tan sólo recorridas por una guirnalda de flores exenta y que sin embargo recuerdan a las que Juan Martín de Andrés había diseñado para las Virtudes del retablo pamplonés.

Las indicaciones que recibió Hermosilla de conservar el cascarón superior debieron ser terminantes, puesto que se ejecutó este elemento tan antitético de las ideas de un arquitecto de gustos academicistas. Sin embargo, el relieve del mismo se aplana hasta quedar reducidos los gajos a la mínima expresión y su decoración a unos relieves sin importancia, prescindiendo de ménsulas, esculturas — sólo los pequeños relieves de san Pedro y san Pablo- y, sobre todo, suprimiendo la habitual gloria con el Espíritu Santo o la Trinidad que solía colocarse en la parte central. En sustitución de ella, Hermosilla coloca en el frontón de remate del cuerpo central del retablo un elemento escultórico, tal como venía siendo admitido y practicado por sus colegas de la Academia Ventura Rodríguez y Francisco Sabatini, el trono de nubes con ángeles sosteniendo la cruz ${ }^{12}$. Pero si su intervención en el cascarón fue importante, la claridad del neoclásico se refleja sobre todo en el cuerpo inferior, donde pensamos que destrozó literalmente el proyecto del arquitecto navarro a pesar del carácter de envoltura del presbiterio que hubo de respetar para no defraudar a los naturales con un retablo exento, que hubiera parecido poca cosa. Los elementos constructivos se colocan en un plano único, apenas resaltado en su parte central, lo que evita la confusión de estilóbatos y cornisas quebrados, origen de calles y cuerpos resaltados o rehundidos. El extenso cuerpo central entre entablamento y banco se explaya a lo ancho del ábside proporcionando un hermoso espectáculo luminoso que no se rompe en ningún punto. El friso y cornisa se simplifican y reducen a unas bandas transversales decoradas con sencillez y elegancia y lo mismo puede decirse del banco, interrumpido sólo por los recuadros que enmarcan las escenas o los evangelistas, emulando los retablos renacentistas. Las imágenes de los cuatro santos y el Salvador centran así toda la atención del espectador y nada empaña el que luzcan en todo su esplendor. El retablo de Irurita es, pese a su retardatario cascarón y su extensión a todo el presbiterio, un retablo neoclásico, precursor del nuevo estilo en los territorios navarros. Su temprana fecha le acredita como tal en un momento en que aún dominaba plenamente el gusto por la composición y decoración abigarrada y confusa propia de tendencias iniciadas medio siglo antes.

El autor de la traza, José de Hermosilla y Sandoval, nacido en Llerena y muerto en 1776, fue arquitecto e ingeniero militar; había sido enviado a Roma por Fernando VI con el encargo de realizar un compendio de reglas de arquitectura, que terminó en $1750{ }^{13}$. Fue director de arquitectura de la Academia de San Fernando desde la apertura de los estudios hasta 1756; luego ocupó algún tiempo el cargo de tesorero, siendo después desplazado de los cargos administrativos; designado académico de mérito, formó parte hasta su muerte de la junta ordinaria de la Academia. Más conocido como teórico que por sus obras arquitectónicas, el llerenense debía estar poco acostumbrado a la traza de retablos. Llaguno sólo cita como suyo un diseño, que califica de «gracioso», para la sacristía de los Trinitarios calzados de Madrid, compuesto de dos columnas y dos pilastras de orden dórico ${ }^{14}$. Su reducida actividad en este campo nada

\footnotetext{
12 La disposición de grupos escultóricos en el centro de frontones partidos que remataban retablos es un recurso decorativo que se aprecia perfectamente en el retablo mayor de la catedral de Segovia, diseñado por Sabatini en 1768 aunque no se terminó hasta 1775/76, que tiene también los ángeles sosteniendo la cruz sobre nubes y los mancebos en adoración sobre la cornisa del frontón. Sin duda conocía Hermosilla el proyecto y utilizó la idea en su diseño. Sabatini colocó más tarde un grupo escultórico semejante sobre la cornisa de la iglesia del Palacio de Aranjuez, encima del altar mayor, si bien con carácter independiente del retablo, que queda más abajo. También Ventura Rodríguez usó este tipo de decoración sobre la cornisa en el retablo de Rentería de 1783.

13 José de Hermosilla y Sandoval, La Architectura Civil de Dn Joseph de Hermossilla y de Sandoval, Roma 1750 (manuscrito). Biblioteca Nacional, Mss. 7573.

${ }^{14}$ Eugenio de Llaguno y Amírola, Noticias de los Arquitectos y Arquitectura de España..., IV, Madrid, $1829,267$.
} 
tiene que ver con la amplísima producción que se conoce de sus colegas Francisco Sabatini y Ventura Rodríguez. Tampoco su labor como teórico, director de los trabajos de reproducción gráfica de los edificios islámicos o tracista de grandes obras públicas, le cualificaban para el encargo. Como ya hemos apuntado, los buenos oficios de su hermano Ignacio, su posible amistad con Pignatelli, que fue quien en definitiva decidió encomendarle la traza, y quizá su buena disposición a llevarlo a cabo con rapidez, pues no tenía a su cargo tantas obras como los dos citados, fueron puntos a su favor. También es posible que el viceprotector conociera que sus ideas arquitectónicas eran bastante más tolerantes que las de Villanueva, por ejemplo, lo que le permitiría someterse sin repugnancia a pautas tan antiacadémicas como los deseos de los comitentes. En todo caso, parece claro que Hermosilla no consideró la obra de Irurita como un timbre de gloria, pues no aparece citada en la biografía que sobre él escribió Llaguno, probablemente basada en relaciones que hicieran personas próximas al arquitecto; no creó con ella escuela, pronto se olvidó esa traza hecha para un retablo muy alejado de la Corte y sus biógrafos no la mencionaron para la posteridad.

El diseño de José de Hermosilla para el retablo de Irurita puede calificarse de atípico en el contexto general del retablo hacia 1770; no encaja en los tipos de los más avanzados diseños neoclásicos ni tampoco en los retrasados, pero numerosos, tardobarrocos que se construían aún. Sus características inusuales responden, como ya se ha explicado, a la labor de síntesis que hubo de realizar Hermosilla al trazar una obra que resultara aceptable a los naturales de la localidad navarra y que a la vez contentara a sus colegas académicos. Con estas limitaciones y pie forzado, la traza de Hermosilla representa un magnífico eslabón de unión entre dos tendencias contrapuestas, el racionalismo arquitectónico que le correspondía como discípulo de Ferdinando Fuga, y el tardobarroco desenfrenado a que había dado lugar la herencia churrigueresca. Del barroco sólo conserva la forma de gran máquina envolvente y la división tradicional en cuerpo bajo y cascarón, pero todo lo demás responde a un clasicismo mesurado cuyo diseño está basado en el elemento constructivo elemental, la columna y la pilastra, desterrando el adorno superfluo.

Diversos aspectos de la traza obedecen exactamente a las propuestas formales de la proporción y buen gusto de los edificios que contiene su Architectura. El orden elegido es el corintio, que junto al compuesto, considera que son los órdenes más perfectos. Los capiteles y el entablamento siguen al pie de la letra el diseño que para el orden corintio incluye el tratado, en especial la cornisa, que observa el triple decorado de dentellones, escocia de ovas y alero con modillones. Entre las alturas de cornisa y columna se observa la proporción de uno a cuatro que propugna Hermosilla como resultado de su observación de los edificios antiguos romanos. Y considerando que el banco sirve de pedestal a las columnas y pilastras, se puede constatar que se respeta igualmente la proporción de un tercio de altura que propugna el arquitecto para la relación entre pedestal y columna con capitel y basa. De este modo, dividida la altura total del edificio - en este caso, retablo- en 19,12 partes corresponderían a la columna con su capitel y basa, 4 al pedestal y 3 al entablamento ${ }^{15}$.

Las columnas sostienen el cuerpo central ligeramente adelantado, a modo de falso atrio. Hermosilla renuncia a despegar esas columnas e introducir un cuerpo excesivamente resaltado que hubiera destruído el efecto de curva cóncava que obligadamente había de ofrecer el retablo. Para ello utiliza la columna adosada, que le permitía crear la impresión pretendida sin debilitar excesivamente la noción de curva. Estas columnas siguen también las reglas: «No pocas vezes se ponen unidas al muro (las columnas) y en este caso lo menos que deven resaltar de él son dos tercios de su diámetro, a fin de evitar la fealdad que ocasionarían las impos-

15 La Architectura... cit., p. 143, punto 24. 
tas si su vuelo excediese el medio de las columnas ...» ${ }^{16}$. La éntasis de la columna era defendida por Hermosilla no sólo para mejorar su aspecto sino, sobre todo, con el fin de que el arquitrabe no se viera precisado a ser grueso. Así se observa en Irurita. Por el contrario, las pilastras conservan la misma anchura en toda su extensión, tal como recomienda su tratado. El resalto de la pilastra debiera ser, según sus indicaciones, de la cuarta parte de su ancho ${ }^{17}$. Las pilastras de Irurita levantan, sin embargo, con un relieve mínimo sobre el plano de pared, si bien ha de tenerse en cuenta que los bordes laterales del retablo presentan un escalonamiento inmediato a la primera pilastra y que en este escalón se prolonga la línea divisoria de capitel y fuste, con lo que el efecto óptico es de adecuado relieve sobre el plano inmediato al muro, que es completamente liso. En cuanto al frontispicio curvo, sigue las proporciones vitruvianas y también observa las propuestas del Tratado de que la cornisa superior del frontón conserve todo su vuelo y se decore con modillones y dentellones idénticos a los que decoraban la cornisa ${ }^{18}$.

Debemos subrayar asimismo algunos puntos de contacto entre la traza del cuerpo central del retablo con la del cuerpo bajo de la catedral cuyo diseño incluye Hermosilla dentro de su Architectura ${ }^{19}$. Evidentemente, la adaptación de la idea de un enorme edificio a la realidad reducida de un retablo y de una fachada recta a paramento curvo obliga a introducir sensibles modificaciones, sin embargo de lo cual aún se aprecian semejanzas mayores que las diferencias. Existe un pórtico central en forma de atrio en la catedral que se convierte en un cuerpo central ligeramente resaltado en el retablo sostenido en ambos casos por cuatro columnas con remate en frontón, columnas que dan lugar en ambos casos a una calle central más ancha con vano de medio punto en la pared de la catedral y hornacina de medio punto en el retablo; entre las dos columnas centrales y las dos extremas de estos cuerpos salientes hay espacios - entrecalles en el retablo- más estrechos que el central, y se usan para los vanos catedralicios o los rectángulos decorativos del retablo, formas adinteladas o de rectángulos. Este atrio se prolonga a los lados en dos alas rematadas en cornisa plana que se inician en una pilastra inmediata a la última columna del atrio y del mismo largo que ésta, a continuación de la cual se abre una calle con hueco terminado en arco de medio punto.

Pero hay algo más en este retablo de Irurita que dice mucho y bien de las ideas de Hermosilla, además de constituir un ejemplo valioso de su arquitectura poco conocida, pues, por desgracia y bien a pesar suyo, son muy pocas las creaciones de él que se han conservado. Como discípulo de Fuga, no podía por menos de sustentar ideas sobre la funcionalidad de los edificios y la relatividad estéril de un culto a ultranza de los órdenes clásicos ${ }^{20}$; pero sus contactos con los arquitectos académicos franceses residentes en Roma añadieron a su pensamiento ciertos matices en el sentido de estimar lo circunstancial de cada obra, es decir, las premisas de un gusto formado en determinado sentido, de un tope de gasto, de unos materiales disponibles. En otro lugar de su Architectura dice: «La decencia hace que el aspecto de una fábrica se disponga de tal suerte que quanto en él haia esté fundado en la razón o authoridad. Pero, principalmente, consiste la decencia de un edificio en el respecto que tiene al estado, a la naturaleza y a la costumbre. Por respecto al estado entiendo la especial disposición que requiere cada especial destino.... El respecto a la naturaleza obliga a que se elijan diversos aspectos para diferentes partes del edificio, a fin de hacerlo más sano y cómmodo...La economía hace que, considerando el architecto el gasto que se ha de hacer, la naturaleza del terreno donde se ha de

\footnotetext{
16 Ibidem, p. 141, punto 17.

17 Ibidem, p. 140, punto 16.

18 Ibidem, p. 137, punto 12

19 Ibidem, pp. 255-262.

${ }_{20}$ Así, Hermosilla dice de Vignola en el Prólogo que, « todo quanto nos dejó escrito se reduce a una confusa explicación de las cinco órdenes. Que es decir, que siendo las tres partes de la Architectura como después veremos, la fortaleza, la commodidad y la hermosura de las fábricas, el Viñola escrivió sólo sobre esta última...» (La Architectura, p. 6, punto 13).
} 
fabricar y la qualidad de los materiales que allí se encuentran, regule la disposición de la fábrica dándole la grandeza y forma competente» ${ }^{21}$.

Sus propuestas arquitectónicas siempre se orientaron, por tanto, a defender una arquitectura realizable, adaptada a las circunstancias de tiempo, lugar y gustos o clima locales ${ }^{22} \mathrm{con}$ vocación práctica, y este retablo es paradigmático en tal sentido. El proyecto de Hermosilla no es un prototipo ideal de retablo de vanguardia, un modelo utópico de tratadista, sino una obra útil, capaz de cumplir su fin. Merecen desprecio los lenguajes artificiales, inútiles, rigoristas que pretenden sujetar la belleza a un orden decorativo. La belleza no depende de unas ideas predeterminadas, sino de la proporción. Dirá Hermosilla: «la ordenación consiste en que las partes del edificio tengan una conveniente grandeza, ia se consideren separadamente o ia se atienda a la proporción de todo el complejo de la obra. La proporción... no es otra cosa que la relación de toda la obra con sus partes y de éstas entre sí y con toda la obra» ${ }^{23}$. De acuerdo a estas ideas, Hermosilla trató de encajar el retablo que se le encargaba en la estructura ya dada de la iglesia y, aún más, de acomodarlo a las apetencias de los naturales; para ello, reclama la situación de la cornisa y ventanas del templo y medida exacta de las paredes del presbiterio y cuando ya ha trazado, recomienda «que el artífice que se encargue de su execución no la equivoque, debe montear por partes el todo, arreglándose a la medida del país y al sitio que según sus dimensiones ha procurado ceñir el retablo a su figura y extensión..» ${ }^{24}$. Este retablo, pese a ser una obra menor, refleja a la perfección las propuestas de Hermosilla sobre la arquitectura.

La trascendencia en Navarra del retablo de Irurita fue, a nuestro entender, mínima y el neoclásico se adentró allí por otros caminos. Sin embargo, existe un retablo mayor, el de la localidad de Azpilicueta, también en el valle del Baztán y muy cercana a Irurita, que presenta caracteres que obligan a juzgarlo inspirado en el modelo de Hermosilla. Este retablo, al igual que otros dos colaterales, han sido atribuídos en diversas publicaciones a Silvestre de Soria, maestro navarro natural de Sesma, y su ejecución se data hacia $1752^{25}$. El motivo de esta datación ha sido quizá la fecha que figura en la imagen de santa Bárbara que ocupa la hornacina central de uno de los colaterales y que la hace también obra de Luis Salvador Carmona ${ }^{26}$. Sin embargo, la imagen, así como otras que existen en la parroquia también atribuídas a Salvador Carmona, pudieron llegar antes de la hechura de los retablos. La atribución del retablo a Silvestre de Soria no se ha justificado documentalmente.

En nuestra opinión, no parece posible que Soria — que en 28 de abril de 1753 cobraba, junto a Diego Martínez, Martín de Artola, Pedro López y Miguel Ximénez por la hechura del Zodiaco que lucía debajo del escudo real de la fachada norte del Palacio Nuevo de Madrid, si

\footnotetext{
${ }^{21}$ La Architectura, pp. 64-65, puntos 12 y 13. El tratado define la hermosura arbitraria o inteligencia objetiva como «un racional uso de los preceptos, y los preceptos mismos practicados en la obra con tal conformidad que se vea en ella aquel decoro y oportuna elección de adornos mediante la que se denomina la obra bien entendida.... y para governarse un Architecto en dar a un edificio esta hermosura apenas hai otras reglas que la propia idea y el buen gusto» (p. 118, punto 8). Junto a esta belleza arbitraria pone otra, que denomina arreglo porque se acomoda a reglas que en un primer momento dependieron del arbitrio de las gentes, pero que una vez establecidas «agrada mucho a los inteligentes ... porque gran parte de ellas está fundada sobre la razón...». Como oportunamente puso de relieve Rodríguez Ruiz (op. cit., 64), Hermosilla tuvo contactos en Roma con los arquitectos franceses relacionados con la Academia francesa matizando su pensamiento racionalista con la incorporación de las teorías de Perrault sobre la Belleza como producto de la idea que cada uno tiene de su perfección, idea que debe ser formada y rectificada de acuerdo a unas reglas.

${ }^{22}$ Así, La Architectura... cit, p. 251. «Es preciso advertir que muchas veces no deverán observarse (las reglas estrictas), a causa de la diversidad de países donde se edifica, ia sea por los excesos del frío, ia por los del calor: pues por proporción de éstos deverán ser diversos los aspectos y lo son las estructuras de las fábricas».

${ }^{23}$ La Architectura, p. 64, punto 12.

${ }^{24}$ Cfr. Documento 2, carta de Hermosilla de 26 de julio de 1770.

${ }_{25}$ El Arte en Navarra cit., 473-474 y 478; Catálogo cit., 322.

${ }^{26}$ Catálogo cit., 323. La firma de la imagen se ha transcrito como Lvis Salvador Carmona y Mur, lo que no deja de ser extraño para este escultor.
} 
bien es posible que hubiera abandonado antes de esa fecha la Corte ${ }^{27}$ - retrocediera desde el estilo bastante más avanzado de Azpilicueta al retardatario rococó en que ejecuta su última obra documentada, los retablos de San Gregorio Ostiense en Sorlada, por los que su viuda cobraba en 1769 y que se supone ejecutados hacia $1765^{28}$. Nada nos indica respecto al estilo de este maestro el retablo de San Lorenzo de Santa María de Tafalla, cuya ejecución se halla documentada en 1760-1761, que responde sin duda a un diseño venido desde Madrid, al igual que la talla que lo decora ${ }^{29}$. Su estilo, de un barroco clasicista de influjo italiano, nada tiene que ver con lo que podía llegar a diseñar Soria.

Pues bien, el retablo de Azpilicueta presenta, con las distancias lógicas que separan la traza de un gran arquitecto de la de un maestro local, muchas concomitancias con el retablo de Irurita. Se trata de un retablo de cascarón que se separa de los modelos navarros al uso. En él está presente la idea de Irurita, esto es, un revestimiento casi plano del muro evitando las rupturas bruscas del estilo barroco tardío, y también una decoración de guirnaldas y orlas de raigambre más neoclásica que rococó. En Azpilicueta la extensión del presbiterio es mucho menor que en Irurita, por lo que las cinco calles de aquél se reducen a tres; el insinuado atrio se convierte aquí en un cuerpo central sobresaliente del plano del muro, formando un baldaquino sostenido por cuatro columnas con hornacina central, terminado, más abajo de la cornisa, en frontón curvo partido coronado por un extraño cuerpo en forma de hornacina que alberga pequeñas esculturas. Este baldaquino es la única parte del retablo que se separa claramente del modelo de Irurita y lo hace quizá para igualar a los colaterales, que presentan la misma estructura. A los lados de la calle central, por la angostura del presbiterio, sólo dos calles laterales entre pilastras, suprimiéndose las entrecalles estrechas que existían en Irurita aunque se disponen también esculturas sobre el estilóbato por delante de las pilastras interiores. Estas calles exteriores llevan hornacinas perforadas con tallas de un santo obispo (quizá también San Eutropio) y San Francisco Javier y encima se disponen pinturas enmarcadas con la apoteosis de ambos santos, también reminiscencia de Irurita. El cascarón presenta una hornacina central que alberga unas esculturas y su encaje con el cuerpo principal del retablo es absolutamente incorrecto, produciendo una fea ruptura chocante con la continuidad que tan bien había quedado resuelta en Irurita. A nuestro entender, este retablo no ha podido ser modelo de Irurita, sino al contrario, pues es un mal trasunto de éste; es más probable que el autor del retablo de Azpilicueta haya sido el propio Echarri que, una vez terminado el de Irurita, emulara ese modelo a petición de los vecinos de Azpilicueta, que no a la inversa.

Nos referiremos ahora a las incógnitas que se plantean en torno a la escultura del retablo de Irurita. El autor de la mitad de la escultura sabemos documentalmente que fue Alfonso Giraldo Bergaz, murciano nacido en 1744, alumno por esos años de Felipe de Castro y de la Real Academia de San Fernando en la que había ganado algunos premios ${ }^{30}$. Era, por tanto, muy joven cuando fue llamado a este encargo, suponiendo que lo fuera al mismo tiempo que Hermosilla trazaba, que es lo normal. Dado que el otro escultor de quien no conocemos el nombre se reservó la

27 A.G.P. Obras de Palacio, Leg. 294. El documento dice lo siguiente: «A Don Diego Martínez, Don Martín de Artola, Don Pedro López, Don Miguel Ximénez, Don Silbestre de Soria, obligados a la egecuzión de un adorno que representa el Zodiaco en piedra blanca de Colmenar de Oreja que se ha de colocar debajo del escudo de Armas Reales de la fachada del Norte del Nuevo Real Palacio..

$$
\begin{aligned}
& \text { - } 16 \text { de junio de } 1750 \text {.............................. } 6.000 \\
& \text { - } 25 \text { de febrero de } 1751 \text {......................... } 5.000 \\
& \text { - } 28 \text { de abril de } 1753 \text {............................... 1.000» }
\end{aligned}
$$

${ }_{28}$ Catálogo cit., Pamplona 1983, II**, 509; El Arte en Navarra cit., 473-474.

29 Ibidem, 480

30 Manuel Ossorio y Bernard, Galería biográfico de artistas españoles del siglo XIX, Madrid 1883-1884, 694; Conde de la Viñaza, Adiciones al Diccionario Histórico, Madrid 1894, IV 36-37; Carmen Rodríguez Rico, «Alfonso Giraldo Bergaz y su relación con la Real Academia de Bellas Artes de San Fernando», Academia 87 (1998), 287-307. 
hechura del Salvador, presuntamente la talla de mayor importancia, pensamos que el encargo de Bergaz fue de segunda mano, esto es, que llegó a él por cesión de ese otro artífice. Su estilo revela una madurez precoz; unido esto a la perfecta unidad de estilo que ofrece todo el conjunto, nos lleva a pensar que su labor se realizó bajo la dirección de ese desconocido escultor.

Hacer propuestas sobre la personalidad de éste no deja de ser arriesgado. Las cinco imágenes responden absolutamente a modelos neoclásicos al uso en la Corte, mesuradas, correctísimas de proporciones, gestos y ejecución, de gran nobleza en los rostros y total acierto en el plegado de paños, destierran todo exceso de sentimiento o actitud exagerada y optan por la dulzura y amabilidad propias de las nuevas tendencias. Hemos repasado la nómina de escultores importantes de la Corte en aquél año y no parece posible identificar en las tallas de Irurita la mano de escultores tales como Roberto Michel o Juan Pascual de Mena, que por ser respectivamente primer escultor de Cámara o Director de Escultura de la Academia estaban en aquel momento por encima de Bergaz en el escalafón de escultores. Felipe de Castro, que ocupaba por entonces el cargo de Director de Escultura compartido con Mena, estaba muy ocupado en los trabajos de escultura del Palacio real y del Palacio del infante don Luis en Boadilla ${ }^{31}$. Sin embargo, aunque Castro no fuera autor directo de las tallas, pudo serlo de su traza y director del trabajo sobre las mismas, porque en 1768, Alfonso Bergaz, tras haber pasado diez años como escultor de la fábrica de Porcelana, se colocó como oficial de escultura en el obrador de Castro ${ }^{32}$. No conocemos ningún otro discípulo de Castro hacia 1770 a quien puedan atribuirse las tallas de Irurita, descartado Manuel Álvarez, cuya lista de obras se conoce suficientemente.

Sin embargo, otro escultor ajeno al círculo de Castro tiene, a nuestro entender, posibilidades de haber ejecutado la mitad de la escultura de Irurita y es Francisco Gutiérrez (1727-1782). Este artífice ostentaba hacia 1770 los cargos teniente director de Escultura de la Academia y escultor de cámara del Rey; perteneciente a la generación inmediatamente anterior a Alfonso Bergaz, tiene una amplia obra centrada preferentemente en la piedra y el estuco. Sin embargo, no desdeñó el trabajo en madera y así Ceán ${ }^{33}$ cita en este material los arcángeles que hizo para los mercedarios calzados de Huete (Cuenca) y también lo serían la estatua de la Humildad que realizó para el retablo de San Isidro el Real tras la reforma que inició Ventura Rodríguez a la expulsión de los jesuitas, otras tallas para Santa Cruz y probablemente la estatua del Salvador para los padres del oratorio de este nombre, todas en Madrid y actualmente desaparecidas. Precisamente a principios de 1770, sólo seis meses antes de presentarse a la aprobación de la Academia la traza de Irurita, hizo una oferta para marchar a Sobrado de los Monjes en Galicia, donde se ocuparía de terminar su retablo ${ }^{34}$, haciendo una oferta bastante más módica que la de Juan Pascual de Mena, que había sido el recomendado para el encargo por la Academia. Gutiérrez no llegó a contratar porque se adelantó con otra propuesta mejor Manuel Álvarez, que era el otro teniente director, a quien se adjudicó finalmente. En este tiempo, por tanto, Gutiérrez estaba libre y deseoso de obtener obras, y quizá la Academia quiso desagraviarle del desaire de Álvarez en el asunto de Sobrado, recomendándole para llevar a cabo la escultura de Irurita.

Estilísticamente hablando, la propuesta no es descabellada, como se puede observar en la comparación del trono de nubes y ángeles de la medalla que hizo Gutiérrez para los franciscanos de Arenas de San Pedro (Ávila) y el trono de nubes y ángeles del Salvador de Irurita ${ }^{35}$.

\footnotetext{
${ }^{31}$ R.A.S.F. 32-14/1. El 14 de febrero de 1772 se excusaba el escultor de no poder aceptar el cargo de director de Perspectiva que le ofrecía la Academia por estar muy ocupado en las obras del Rey y del Infante.

32 R.A.S.F. 173-1/5.

33 Juan Agustín Ceán Bermúdez, Diccionario Histórico..., Madrid 1800, II, 246-251.

${ }^{34}$ Ramón Otero Túñez, «El Retablo de Sobrado y el Neoclasicismo», Cuaderno de Estudios Gallegos XLVII (1960), 339-340.

${ }^{35}$ La medalla de San Pedro de Alcántara fue grabada por Manuel Salvador Carmona y es corriente su reproducción en repertorios de láminas.
} 
Existe, además, otro dato favorable a esta hipótesis: en un memorial que presentó Bergaz fechado el 28 de marzo de 1786 manifiesta que terminó algunas obras que dejó pendientes a su muerte Francisco Gutiérrez ${ }^{36}$, lo que indica que probablemente había tenido alguna relación con él anterior a este momento.

Muy interesante nos parece el examen de las escenas grandes en relieve que decoran el banco. Si en las tallas de gran tamaño era casi imposible distinguir dos manos aún sabiendo la existencia de dos autores, la Adoración de los pastores y la Adoración de los Magos pertenecen claramente a dos estilos diferenciados. La escena de los Magos presenta una multitud de figuras menudas que se agolpan en primer plano, llenando casi totalmente el espacio disponible, lo que elimina perspectiva y paisaje. Por el contrario, la escena del Portal de Belén presenta un macizo grupo central formado por las figuras de la Sagrada Familia mientras a los lados se abre una visión de paisaje en perspectiva donde se colocan sólo cinco figuras humanas de tamaño relativamente grande, pero que no estorban la vista del fondo. Los tipos humanos son muy diferentes en uno y otro relieve y también la técnica de definición de contornos y la altura de la talla. El Portal de Bergaz no puede por menos de recordar las figuras de los belenes napolitanos, tal como ya señalaba el Catálogo de Navarra. La inspiración, sin embargo, proviene de los tipos pastoriles utilizados en la Fábrica de Porcelana de la China del Buen Retiro, donde Bergaz trabajó diez años (1758-1768) en contacto con el napolitano José Gricci, que tenía encomendada su dirección. Pues bien, si el relieve de la Adoración de Pastores parece muy acorde con lo que podía ser estilo propio de Bergaz, en cambio, la composición del relieve de la Adoración de los Magos y los tipos humanos de sus figuras recuerdan, salvadas las distancias cronológicas y de escenario, al tipo de figura menuda y relieve más plano que Gutiérrez usaba, por ejemplo, en su boceto para el relieve de La fundación de la Academia ${ }^{37}$, fechado en 1764; varios grupos de figuras ocupan la superficie del plano, con unas levísimas referencias a un escenario de interior en el escaso espacio superior que queda libre, de modo semejante al modo en que el relieve de Irurita deja ver unos trozos de cielo y nubes.

\section{DOCUMENTOS}

1. Correspondencia mantenida entre José Ignacio de Goyeneche, Vicente Pignatelli y José de Hermosilla en relación con el retablo de Irurita.

Archivo de la Real Academia de Bellas Artes, 34-2/2.

YRURITA (Navarra)

\section{7-6-1770}

Mui señor mío: En la yglesia parroquial del lugar de Yrurita, valle de Baztán, en el reyno de Navarra, se ha de construir un retablo de mui considerable coste; y para él se ha trabajado por Juan José de Echarri el diseño adjunto: Se desea el acierto y para él se ocurre a la Real Academia de San Fernando que V.S. preside, y siendo notorio el celo con que ese ilustre cuerpo promuebe en veneficio público las Artes y el esmero con que cuida de la perfeccción de sus produciones, me valgo del favor a V.S. suplicándole se sirva presentarla el referido diseño a fin de que le examine y de la censura que merezca para que arreglándose a sus sabias advertencias se execute la obra con el acierto que se solicita. Con este motibo renuevo a V.S. mi verdaderos deseos de serbirle y ruego a Nuestro Señor guarde a V.S. muchos años

Madrid, 7 de junio de 1770.

Besa la mano de V.S. su más favorecido, reconocido y obligado servidor, J.Y. de Goyeneche

Sr. D. Vicente Pignatelli.

[Nota:] J.O. de 10 de junio de 1770.

\footnotetext{
${ }^{36}$ R.A.S.F. $173-1 / 5$

37 Para Portela, este relieve es un boceto del que luego realizó para decorar el frente de la urna del sepulcro de Fernando VI en las Salesas. Cfr. Francisco Portela Sandoval, Francisco Gutiérrez y el sepulcro del Rey Fernando VI, en El arte en las Cortes europeas del siglo xVIII, Madrid 1987, 600-607.
} 
Reprobado enteramente. Remítanse diseños de la planta y corte interior de esta yglesia con demostración del sitio donde debe colocarse este altar y con noticia de la materia de que ha de construirse para que en esta corte se hagan dibujos arreglados

\section{1-6-1770}

Muy Señor mío: Presenté a la Academia el diseño del retablo que se quiere hacer para la parroquial de Yrurita y por la adjunta copia de los acordado ayer en este asunto verá V.S. la reprobación del citado diseño y que quanto está de nuestra parte ayudaremos a desterrar el mal gusto y a que no se gaste el dinero en obras que nos afrentan. Sírvase V.S. hacer que se evacúen los puntos que contiene el acuerdo en la seguridad de que con el mayor gusto dispondrá la Academia lo que ofrece y yo le tendré igual sirviendo a V.S. en esto y en quanto sea de su agrado.

Dios guarde a V.M. muchos años como deseo. Madrid a 11 de junio de 1770. B.1.m. de V.S. Sr. D. Vicente Pignatelli

Sr. Don Joseph Ygnacio de Goyeneche.

[Nota al margen:] Con este papel se pasó la copia del acuerdo de 10 de junio que se cita.

\section{6-7-1770}

Mui señor mío: Por los adjuntos papeles reconocerá V.S. los términos en que satisfacen a las adbertencias de la Academia los interesados en la execución del retablo que demuestra el diseño que presenté a V.S. con papel de 7 del pasado y suplico a V.S. que continualdome [sic] sus honrras se sirba hazerlos presente a la Academia a fin de que en su vista y con presencia del citado diseño se forme otro arreglado y oportuno a la idea de aquellos naturales.

Espero merecer a V.S. esta nueva fineza y que asegurado de mi reconozimiento y obediencia a sus preceptos me emplee V.S. siempre con la propia confianza en quanto sea de su obsequio. Nuestro Señor guarde a V.S. muchos años como así deseo. Madrid 6 de julio de 1770.

Besa la mano de V.S. Su más favorecido atento servidor, Joseph Ygnacio de Goyeneche.

Sr. D. Vicente Pignateli.

[Nota:] J.O. de 8 de julio de 1770.

El Señor Hermosilla quedó encargado de la execución del nuevo diseño.

26-7-1770

Excmo Sr.

En Junta Ordinaria de 8 del corriente me mandó V.E. formase una idea para el retablo del altar mayor de la yglesia parroquial de Yrurita en el reyno de Navarra. He procurado desempeñar este encargo lo más breve que he podido, y lo menos mal que alcanza mi talento, en cuio supuesto no me queda otra satisfacción que la de que le agrade a V.E.

Debo hacer presente para que el artífice que se encargue de su execución no la equivoque, debe montear por partes el todo, arreglándose a la medida del país y al sitio que según sus dimensiones ha procurado ceñir el retablo a su figura y extensión. He dispuesto la colocación de los cinco Santos que contiene en una misma altura, evitando poner unos nichos sobre otros por ser feo y contra la buena decorazión.

El Sagrario o custodia queda mui cómoda para exponer a su Magestad con decoro y magnificencia; el resto me parece se demuestra así en el plano como en la elevación y perfil con quanta claridad es necesaria y cabe en las reglas del Arte. V.E. disponga espresamente de mi obediencia. Madrid, 26 de julio de 1770

Exmo.Sr. Joseph de Hermosilla.

\section{3-8-1770}

Muy Señor mío: En la Junta de ayer vio la Academia la idea que por su encargo ha formado el académico de honor don Joseph de Hermosilla para el retablo de la yglesia mayor de Yrurita; y se aprobó como la más oportuna y arreglada al sitio. Acordó la Junta pasarla (como lo executó) a manos de V.S. y si en la execución se ofreciese a los artífices alguna duda o dificultad se servirá V.S. prevenirles la comuniquen para ministrarles las luces y advertencias necesarias que en ello y en quanto sea obsequio de V.S. se empleará mui gustosa la Academia, como yo en servirle en quanto fuere de su agrado.

Dios guarde a V.S. muchos años como deseo. Madrid a 13 de agosto de 1770. Sr. Don Joseph Ygnacio de Goyeneche.

2. Acuerdos de las Juntas Ordinarias de la Real Academia de San Fernando referidos al retablo de Irurita.

Archivo de la Real Academia de Bellas Artes, Libro 3/83.

Junta ordinaria de 10 de junio de 1770

(fol. 25) El Sr. Viceprotector dió cuenta de un papel con que el señor don Joseph Ygnacio Goyeneche con fecha de siete de este mes acompaña un diseño hecho por (fol.25v $\mathrm{v}^{\circ}$ ) Juan Joseph de Echarri para el reta- 
blo que se ha de hacer en la Yglesia Parroquial del lugar de Yrurita en Navarra y pide a la Academia lo examine y censure a fin de que construyendose esta obra con arreglo a sus advertencias se consiga el acierto que desea.

Se examinó atentamente por los vocales de Arquitectura, a saber los académicos de honor don Joseph de Hermosilla y don Luis de Lorenzana, los directores don Ventura Rodríguez y don Diego Villanueva y el teniente director don Miguel Fernández. Todos contestes informaron que el citado diseño es monstruoso, sin idea, sin arte, sin regla ni buen gusto. Los profesores de Pintura y Escultura con igual uniformidad fueron del mismo sentimiento en cuya consequencia declaró la Junta que debe reprobarse enteramente y reprobó el espresado diseño.

Pero con el deseo de contribuir con quanto está en su arbitrio al decoro del templo en que ha de servir y a que no se malgasten con oprobio a la Nación los caudales, acordó se participe al señor Goyeneche la reprobación del citado diseño; y que conviene se traiga la planta y corte interior de la referida parroquia, en diseños geométricos que señalen con exactitud la altura interior la de las cornisas y ventanas, el sitio donde se ha de poner el retablo; que se exprese quánto es el caudal destinado para él; si se ha de hacer de jaspes o de madera, con todas las demás noticias de hecho necesarias, a fin de que la Junta disponga que con presencia de todas estas circunstancias se forme un diseño arreglado y oportuno, que mereciendo los gastos que se han de hacer, sirva dignamente al culto de Dios y a la decencia de aquel templo.

Junta ordinaria de 8 de julio de 1770.

(fol. $29 \mathrm{v}^{\circ}$ ) Leído el acuerdo de la precedente, di cuenta de que haviendo comunicado el Señor Viceprotector lo resuelto en ella sobre el retablo de Yrurita al señor don Joseph Ygnacio Goyeneche, este cavallero lo participó a los interesados de aquel pueblo, los quales en su consequencia remitieron una planta de la yglesia y una relación de las circunstancias que desean que tenga su retablo, expresando ha de ser de madera, cuyo material tienen prevenido y para costearlo de siete a ocho mil pesos. El señor Goyeneche con fecha de 6 de este mes remite estos documentos al señor Viceprotector pidiendo a la Junta se sirva mandar se forme un diseño oportuno y en lo posible conforme a las ydeas de los naturales que lo costean. La Junta convino en ello, y este Viceprotector lo encargó al señor académico de honor Joseph de Hermosilla a quien se entregaron todos los antecedentes para formar el diseño.

\section{Junta ordinaria de 12 de agosto de 1770.}

(fol. $34 v^{\circ}$ ) El señor académico de honor don Joseph de Hermosilla presentó el diseño $\left(35 v^{\circ}\right)$ que por encargo de la Junta ha hecho para el retablo de la yglesia mayor de Yrurita y entregado al examen de los señores Profesores de Arquitectura se retiró de la Sala en tanto le vieron los de todas las Artes e informaron que la idea era muy oportuna y arreglada al sitio, en cuya consequencia acordó la junta se pase al señor don Joseph Ygnacio de Goyeneche para su execución avisándole que en las dudas o dificultades que se le ofrezcan a los artífices que la han de executar ocurran a la Academia y en este estado volvió a la sala el señor Hermosilla a quien la Junta dió las gracias por la puntualidad con que, sin embargo de sus notorias ocupaciones, a desempeñado este encargo.

* Deseamos agradecer al señor párroco de Irurita, don Isidro Herguedas Sukia, su amabilidad y las facilidades prestadas para el estudio del retablo y de la documentación allí conservada. 